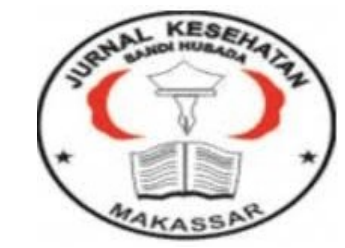

\author{
Jurnal Ilmiah Kesehatan Sandi Husada \\ hhttps://akper-sandikarsa.e-journal.id/JIKSH \\ Volume 11, Nomor 1, Juni 2020, pp;505-511 \\ p-ISSN: 2354-6093 dan e-ISSN: 2654-4563 \\ DOI: $10.35816 /$ jiskh.v10i2.337
}

\title{
Studi Pemanfaatan Antenatal Care Pada Ibu hamil Di Puskesmas Aeng-Towa
}

Study of use Of Antenatal Care in Pregnancy Mother in Puskesmas Aeng-Towa

\author{
Yantimala Mahmud \\ Akademi Keperawatan Makassar,
}

\section{Artikel info \\ Artikel history:}

Received; Mei 2020

Revised: Juni 2020

Accepted; Juni2020

\begin{abstract}
Abstrak
Latar Belakang: AKI di Indonesia masih sangat tinggi, sebanyak 228 ibu meninggal dunia pada setiap 100.000 kelahiranhidup. Sementara target pemerintah adalah menurunkan AKI menjadi I02 per 100.000 kelahiran hidup pada tahun 2015 (Profil Kesehatan Indonesia Tahun 2012). Cakupan kunjungan ibuhamil K1 di Indonesia pada Tahun 2011 adalah 95,7l \% dari target 95\% dan kunjungan ibu hamil K4 sebanyak 88,27 \% dari target $90 \%$ (Kemenkes RI, 2012). Tujuan: Untuk memperoleh gambaran tentang pemanfaatan antenatal care pada ibuhamil di Puskesmas Puskesmas Aeng-Towa Kec. Galesong UtaraTahun 2019. Metode: Jenis penelitian yang digunakan adalah penelitian Survey dengan pendekatan Deskriptif untuk mendapatkan gambaran pemanfaatan antenatal care pada ibuhamil di Puskesmas Aeng-Towa Kec. Galesong UtaraTahun 2019. Hasil Penelitian: lbu Hamil dengan antenatal care lengkap sebanyak 30 responden (60\%)dan yang tidak lengkap sebanyak 20 responden (40,0\%), Pemanfaatan antenatal care terbanyak pada ibu hamil yang berpendidikan rendah sebanyak 42 respnden (84,0\%), Pemanfaatan antenatal care lebih banyak pada ibu hamil yang tidak bekerja sebanyak 42 responden (84.0\%), Pemanfatan antenatal carelebih banyak dimanfaatkan oleh ibu hamil yang memiliki parita srendah sebanyak 48 responden (96.0\%), Pemanfaatan antenatal care lebih banyak responden yang berpendapat bahwa sikap petugas yang baik adalah sebanyak 45 (90.0\%). Kesimpulan: terdapat hubungan pendidikan, pekerjan, paritas, sikap ibu terhadap antenatal care
\end{abstract}

\begin{abstract}
Background: MMR in Indonesia is still very high, as many as 228 mothers die in every 100,000 live births. While the government's target is to reduce MMR to 100,000 per 100,000 live births in 2015 (Indonesian Health Profile 2012). Coverage of K1 mothers visiting Indonesia in 2011 was $95.71 \%$ of the target of $95 \%$ and K4 visits for pregnant women were $88.27 \%$ of the target of $90 \%$ (Ministry of Health Republic of Indonesia, 2012). Aim: This study aims to obtain an overview of the use of antenatal care in pregnant women in Puskesmas Aeng-Towa Puskesmas. Galesong Utara Tahun 2019. Method: thisis survey research with a descriptive method to get an overview of the use of antenatal care in mothers at PuskesmasAengTowa Kec. Galesong Utara 2019. Results: Pregnant mothers with
\end{abstract}


complete antenatal care were 30 respondents (60\%) and incomplete were 20 respondents (40.0\%). The highest utilization of antenatal care in pregnant women with low education was 42 respondents $(84,0 \%)$, Utilization of antenatal care is more in pregnant women who do not work as many as 42 respondents (84.0\%), Utilization of antenatal care is more utilized by pregnant women who have a parita as low as 48 respondents (96.0\%), more use of antenatal care respondents who think that the attitude of a good officer is 45 (90.0\%). Conclusion:this study showed that there is relationship between education, work, parity, mother's attitude to the antenatal care

Keywords:

Antenatal Care;

Pregnancy;

Parity;
Corsponden author:

Email: alifkeke67@gmail.com

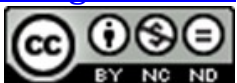

artikel dengan akses terbuka dibawah lisensi BCC BY NC ND-4.0

\section{Pendahuluan}

Kehamilan merupakan suatu hal yang fisiologis yang menjadi dambaan setiap pasangan suami istri.Kehamilan sebagai hal yang fisiologis dan menjadi patofisiologis jika terdapat kelainan yang berhubungan dengan kehamilan yang dapat menyebabkan kematian. Salah satu faktor yang dapat menyebabkan kematian adalah anemia(Rahayu,2011). antenatal adalah memantau kemajuan kehamilan untuk memastikan kesehatan ibu dan tumbuh kembang janin, meningkatkan mempertahankan kesehatan fisik, maternal dan social ibu dan bayi, mempersiapkan peran ibu dan keluarga dalam menerima kelahiran bayi agar dapat tumbuh kembang secara normal, mempromosikan dan menjaga kesehatan fisik dan mental ibu dan bayi dengan pendidikan, nutrisi, kebersihan diri, dan proses kelahiran bayi, mendeteksi dan menatalaksanakan komplikasi medik bedah, atau obstetry selama kehamilan, mengembangkan persiapan persalinan serta persiapan menghadapi komplikasi, membantu menyiapkan ibu menyusui dengan sukses, menjalankan nifas normal dan merawat anak secara fisik psikologis dan sosial (Marni, 2011).

Menurut data WHO, sebanyak 99\% kematian ibu akibatmasalah persalinan pada tahun 2012. Masalah angkakematianibu (AKI) merupakan salah satu indikator status kesehatan masyarakat.Angka kematian ibu di Indonesia masih tinggi dibandingkan negara Associationof south east Asia Nations (ASEAN) lainya.Menurut badan penelitian dan pengembangan Depkes RI,AKI tahun 2009 mencapai 226 per 100.000kelahiran hidup.Angka ini turun dibandingkan AKI hasil survey Demografi Kesehatan Indonesia (SDKI) tahun 2007 yang mencapai 228 per 100.000 kelahiran hidup (Depkes RI,2010). Berdasarkan sasaran pembangunan Milenium atau Milenium Development Goals (MDGs) yaitu menurunkan Angka Kematian Ibu sampai $3 / 4$ risiko jumlah kematian ibu (Mboi, 2012). Cakupan kunjungan ibu hamil K1 di Indonesia pada Tahun 2011 adalah95,7l \% dari target 95\% dan kunjungan ibuhamil K4 sebanyak 88,27\% dari target 90 \% (Kemenkes RI,20l2).

Berdasarkan Data dari Puskesmas Puskesmas Aeng-Towa Kec. Galesong Utara pada tahun 2018 menunjukan bahwa jumlah ibu hamil yang melakukan pemeriksaan kehamilan pada Kl 515 orang, sedangkan pada K4 mencapai425 orang. Dari uraian di atas maka penulis tertarik untuk meneliti tentang pemanfaatan antenatal care pada ibu hamil di Puskesmas Puskesmas Aeng-Towa Kec. Galesong Utara Tahun 2019. Tujuan penelitian ini untuk memperoleh gambaran tentang pemanfaatan antenatal care pada ibu hamil di Puskesmas Puskesmas Aeng-Towa Kec. Galesong UtaraTahun $2019 .$. 


\section{Metode}

Jenis penelitian yang digunakan adalah penelitian Survey dengan pendekatan Deskriptif untuk mendapatkan gambaran pemanfaatan antenatal care pada ibuhamil di Puskesmas Aeng-Towa Kec. Galesong Utara Tahun 2019. Penelitian ini dilaksanakan di Puskesmas Aeng-Towa Kec. Galesong Utara Mulai tanggal 20 Desember 2019 sampai dengan 30 Maret 2020. Populasi dalam penelitian ini adalah semua ibu hamil yang memeriksakan kehamilannya di Puskesmas Aeng-Towa Kec. Galesong Utara periode Oktober - November 2019 yaitu 90 orang. sampel dalam penelitian ini adalah semua ibuhamil yang memeriksakan kehamilannya di Puskesma Aeng-Towa Kec. Galesong Utarayang diambil secara accidental sampling yaitu mengambil sampel yang adapada saat penelitian berlangsung. Analisis yang digunakan yaitu analisis univariat dengan distribusi frekuensi.

\section{Hasil Dan Pembahasan}

Tabel 1 DistribusiRespondenBerdasarkanUmur di Puskesmas Aeng-Towa Kec. Galesong UtaraTahun 2019

\begin{tabular}{lll}
\hline Karakteristik responden & $\mathbf{n}$ & $\mathbf{( \% )}$ \\
\hline Umur (Tahun) & & \\
$17-22$ & 19 & 38,0 \\
$23-30$ & 14 & 28,0 \\
$31-38$ & 17 & 34,0 \\
Usia Kehamilan (bulan) & & \\
$1-3$ & 12 & 24,0 \\
$4-6$ & 16 & 32,0 \\
$7-9$ & 22 & 44,0 \\
\hline
\end{tabular}

Sumber: Data Primer 2019

Tabel 2 Distribusi RespondenBerdasarkan variabel Penelitian di Puskesmas AengTowa Kec. Galesong UtaraTahun 2019

\begin{tabular}{lcc}
\hline Variabel Penelitian & N & (\%) \\
\hline Pemanfaatan ANC & & \\
$\quad$ Memanfaatkan (K1-K4) & 30 & 60,0 \\
$\quad$ Tidak Memanfaatkan (K1-K4) & 20 & 20,0 \\
$\begin{array}{l}\text { Pendidikan } \\
\quad \text { SMA }\end{array}$ & 8 & 16,0 \\
$\quad$ SD & 42 & 84,0 \\
Pekerjaan & & \\
$\quad$ Bekerja & 8 & 16,0 \\
$\quad$ TidakBekerja & 42 & 84,0 \\
Paritas & & \\
$\quad$ Risiko Tinggi & 2 & 4,0 \\
$\quad$ Risiko Rendah & 48 & 96,0 \\
$\quad$ Bikap Petugas & & \\
$\quad$ Tidak Baik & 45 & 90,0 \\
\hline
\end{tabular}

Sumber: Data Primer 2019 
Tabel 3 Distribusi Pendidikan Ibu, Pekerjaan, Paritas, Dan Sikap Petugas dengan PemanfaatanAntenatal Care di PuskesmasAeng-Towa Kec. Galesong Utara Tahun 2019

\begin{tabular}{lcccccc}
\hline \multicolumn{7}{c}{ Pemanfaatan Antenatal Care } \\
\hline \multicolumn{1}{c}{ Variabel } & \multicolumn{2}{c}{ Lengkap } & \multicolumn{2}{c}{ Tidak Lengkap } & \multicolumn{2}{c}{ Jumlah } \\
\cline { 2 - 7 } & $\mathbf{n}$ & $\mathbf{\%}$ & $\mathbf{n}$ & $\mathbf{\%}$ & $\mathbf{n}$ & $\mathbf{\%}$ \\
\hline $\begin{array}{l}\text { Pendidikan Ibu } \\
\quad \text { Tinggi }\end{array}$ & 6 & 20,0 & 2 & 10,0 & 8 & 16,0 \\
$\quad \begin{array}{l}\text { Rendah } \\
\text { Pekerjaan Ibu }\end{array}$ & 24 & 80,0 & 18 & 90,0 & 42 & 84,0 \\
$\quad$ Bekerja & 4 & 13,3 & 4 & 20,0 & 8 & 16,0 \\
$\quad$ Tidak Bekerja & 26 & 86,7 & 16 & 80,0 & 42 & 84,0 \\
$\begin{array}{l}\text { Paritas } \\
\quad \text { Resiko Rendah }\end{array}$ & 17 & 56,6 & 11 & 55,0 & 28 & 56,0 \\
$\quad$ Resiko Tinggi & 13 & 43,4 & 9 & 45,0 & 22 & 44,0 \\
Sikap Petugas & & & & & & \\
$\quad$ Baik & 27 & 90,0 & 18 & 90,0 & 45 & 90,0 \\
$\quad$ Tidak Baik & 3 & 10,0 & 2 & 10,0 & 5 & 10,0 \\
\hline$\quad$ Jumlah & 30 & 100,0 & 20 & 100,0 & 50 & 100,0 \\
\hline Sumber: Data Primer 2019 & & & & &
\end{tabular}

\section{Pembahasan}

\section{Pemanfaatan Antenatal Berdasarkan Pendidikan}

Berdasarkan hasil penelitian ditemukan bahwaibu pendidikantinggi dengan pemanfaatan antenatal care lengkap sebanyak 6 responden $(20,0 \%)$ dibanding responden pada pendidikan tinggi dengan pemanfaatan antenatal care tidak lengkap sebanyak 2 responden $(10,0 \%)$. Sedangkan 42 responden sebagian besar pendidikan rendah dengan pemanfaatan antenatal care lengkap sebanyak 24 responden $(80,0 \%)$ dibandingkan pendidikan rendah 18 responden $(90,0 \%)$. Hal ini menunjukan bahwa ibu yang berpendidikan rendah memiliki pemahaman yang cukup baik tentang masalah kehamilanya, yang walaupun kurang pengetahuannya. Hasil tabulasi silang menunjukan bahwa dari 50 ibu hamil berdasarkan pendidikan tinggi dengan memanfaatkan antenatal caresebanyak 6 responden $(20.0 \%)$ dan responden yang berpendidikan rendahyaitu 24 responden $(80.0 \%)$ sedangkan yang memanfaatkan antenatalcareyaitu $30(60,0 \%)$ dan yang tidak memanfaatkan yaitu $20(40,0 \%)$.

Tingkat pendidikan yang dimiliki oleh setiap orang dalam jangka waktu lama akan memungkinkan orang tersebut menggunakan nalarnya, apapunyang diberikan kepadanya baik dalam bentuk inovasi maupun yang lainnya. Demikian halnya dengan seorang ibu hamil, jika pendidikan ibu cukup maka, akan menggunakan nalarnya sehingga dapat memahami suatu penyuluhan termasuk menyuluh kesehatan ibu dan anak lebih khusus tentang ANC.

\section{Pemanfaatan Antenatal Berdasarkan Pekerjaan Ibu}

Berdasarkan hasil penelitian diperoleh ibu hamil yang bekerja dengan memanfaatkan antenatal care lengkap sebanyak 4 responden $(13,3 \%)$ dan ibu yang bekerja dengan tidak memanfaatkan antenatal caresebanyak 4 responden $(20,0 \%)$. Sedangkan 42 responden sebagianbesaribu yang tidak bekerja dengan memanfaatkan antenatal care lengkap 26responden $(86,7 \%)$ dan ibu yang tidak bekerja dan tidak memanfaatkan antenatal 
caresebanyak 16 responden (80,0\%).

Hasil tabulasi silang menunjukan bahwa dari 50 ibu hamil berdasarkan pekerjaan ibu dengan memanfaatkan antenatal care sebanyak $4(8,0 \%)$ dan responden yang tidak bekerja dengan memanfaatkan antenatal care sebanyak 26 (86,7\%). sedangkan yang bekerja dengan memanfaatkanantenatal careyaitu $8(16,0 \%)$ dan yang tidak bekerja dengan memanfaatkan yaitu $42(84,0 \%)$. Hasil penelitian ini sejalan dengan penelitian Herlinti di Puskesmas Sidorejo Pagar Alam (2011), ibu yang tidak bekerja dengan memanfaatkan Antenatal care lengkap sebanyak 79,81 \% dan ibu bekerja dengan memanfaatkan antenatal care lengkap sebanyak30,29\%. Berdasarkan hasilpenelitian menunjukkan bahwa dari 50 responden $(100,0 \%)$ dengan memanfaatkan antenatal care tidaklengkap lebih banyak pada ibutidak bekerja yaitu $42(61,9 \%)$ dan yang bekerja 8 responden(44,4\%). hal ini disebabkan karena factor ekonomi, jarak rumah, serta pengetahuan ibu hamil yang kurang terhadap pentingnya pemanfaatan antenatal care.

\section{Pemanfaatan Antenatal Berdasarkan paritas}

Berdasarkan hasil penelitian yang di peroleh sebagian besar paritas dengan resiko rendah yang memanfaatkan antenatal care lengkap sebanyak17 responden $(56,6 \%)$ Dan paritas dengan resiko rendah yang tidak memanfaatkan antenatal care sebanyak 11 responden (55,0\%). Sedangkan 22 responden sebagian besarparitas dengan resiko tinggi yang memanfaatkan antenatal care lengkap sebanyak 13 responden (43,4\%). Dan paritas dengan resiko tinggi yang tidak memanfaatkan antental care sebanyak 9 responden $(45,0 \%)$. Paritas adalah jumlah anak yang dilahirkan oleh seorang ibu baik lahir maupun lahir mati. Hal ini menunjukan bahwaibu-ibu primigravida kurang memahami masalah paritas yang berisiko tinggi dan akan menyebabkan kematian, petugas kesehatan perlu memberikan informasi atau penyuluhan kepada ibu yang beresiko terhadap paritas serta melakukan pengawasan bagi wanitayang paritas tinggi, selain itu meminimalkan semua bahaya yang mengancam perkembangan janin.

Hasil tabulasi silang menunjukkan bahwadari 50 ibu hamil berdasarkan paritas tinggidengan memanfaatkan antenatal care sebanyak13 responden $(43,4 \%)$ dan paritas rendah sebanyak17 responden $(56,6 \%)$ sedangkan paritastinggi dengan memanfaatkan antenatal careyaitu. $2(4,0 \%)$ dan paritas rendah dengan memanfaatkan antenatal care yaitu 48(96,0\%). Sedangkan ibuhamil denganparitas $\geq 3$ memanfaatkan antenatal oleh karena mereka sudah memiliki pengalaman yang lebih banyak dalamhal kehamilan dan proses melahirkan, sehingga membuat mereka merasa malas maupun bosan untuk memeriksakan kehamilan dan menganggap kehamilan adalah hal yang sudah biasa dialami. Menurut Moctar (1998). Paritas l dan lebih dari 3 memiliki risiko tinggi komplikasi yang mungkin terjadi pada ibu dengan paritas tinggi adalah pendarahan antepartum, hipertensi dan diabetes melitus. Sehingga untuk mencegah komplikasi tersebut ibu dengan paritas tinggi sangat perlu memanfaatkan antenatal Care pada masa kehamilan.

\section{Pemanfaatan Antenatal BerdasarkanSikap Petugas}

Berdasarkan hasilpenelitian yang diperolehbahwa sikap petugas baik yang memberikan pelayanan lengkap sebanyak 27 responden (90.0\%). Dansikap petugas baik yang tidak memberikan pelayanan antenatal care sebanyak 18 responden (90,0\%). Sedangkan 5 responden sebagian besar sikap petugas tidak baik yang memberikan pelayanan antenatal care lengkap sebanyak 3 responden(100,0\%). Dan sikap petugas tidak baik sebanyak 2 responden $(100,0 \%)$. Hal ini menunjukan bahwa petugas kesehatan memiliki pengetahuan 
dan keterampilan melalui pendidikan di bidang kesehatan dukungan petugas kesehatan sangat diharapkan oleh ibu-ibu hamil baik dukungan informasi, dimana perasaan subjek bahwa lingkungan (petugas kesehatan memberikan informasi yang jelas mengenai hal-hal yang berhubungan dengan kehamilan, selain itu perlu fasilitas yang harus tersedia agar masyararakat dapatmemanfaatkan pelayanan antenatal denganbaik, selain fasilitas yang harus tersedia agar masyarakat dapat memanfaatkan pelayanan antenatal maka harus diperhatikan juga tenaga kesehatan dan sumber daya manusia (SDM). Kinerja yang dihasilkan oleh seorang tenaga kesehatan sangat mempengaruhi kulitas dari pelayanan yang diberikan.

Hasil tabulasi silang menunjukan bahwadari 50 ibu hamil berdasarkan sikap petugasbaik sebanyak 27 responden $(90,0 \%)$ dan sikap petugastidak baik dengan memanfaatkan antenatal care sebanyak 3 responden (I0,0\%) sedangkan petugas baik dengan memanfaatkan antenatal care yaitu 45responden (90,0\%) dan sikap petugas tidak baik dengan memanfaatkan antenatal careyaitu 5 responden $(10,0 \%)$. Petugas kesehatan hendaknya melayani pasien tidak hanyasebagai orang perorangan melainkan sebagai anggota keluarga bahkan sebagai anggota masyarakat sekitarnya, memberikan pelayanan kesehatan secara lengkap dan sempurna.

Sikap merupakan suatu kecenderungan jiwa atau perasaan yang relative tetap terhadap kategori tertentu dari objek, orang atau situasi. Sikap menggambarkan suatu kumpulan keyakinan yang selalu mencakup aspek evaluative sehingga selalu dapat diukur dalam bentuk baik atau buruk, positif ataunegatif. Dalam penelitian sikap yang utuh pengetahuan, pikiran, keyakinan dan emosi memegang peranan penting sikap merupakan hal yang kompleks dan untuk merubahnya diperlukan proses yang tidak sederhana berdasarkan pengetahuan, kepercayaan dan ide mereka tentang hal-hal terkait dengan antenatal care.

\section{Simpulan Dan Saran}

Ibu Hamil dengan antenatal care lengkapsebanyak 30 responden (60\%)dan yang tidak lengkap sebanyak 20 responden (40,0\%), Pemanfaatan antenatal care terbanyak pada ibu hamil yang berpendidikan rendah sebanyak 42 responden $(84,0 \%)$, Pemanfaatan antenatal care lebih banyak pada ibu hamil yang tidak bekerja sebanyak 42 responden (84.0\%), Pemanfatan antenatal care ebih banyak dimanfaatkan oleh ibuhamil yang memiliki paritas rendah sebanyak 48 responden (96.0\%), Pemanfaatan antenatal care lebih banyak responden yang berpendapat bahwa sikap petugas yang baik adalah sebanyak 45 (90.0\%.

Diharapkan kunjungan atau pemeriksaan selama masa hamil dilakukan secara rutin dan ibu hamil harus berkonsultasi segera apabila terjadi sesuatu keluhan walaupun belum sampai pada waktu untuk kunjungan yang ditentukan. Ibu hamil yang berpendidikan rendah rajin memanfaatkan antenatal karena setiap kunjungan antenatal petugas kesehatan akan memberikan penyuluhan tentang pentingnya pemanfaatan antenatal agar kesehatan ibu dan anakterjamin. Sikap petugas terhadap pemanfaatan antenatal care terus ditingkatkan agar ibu hamil merasa senang terhadap pelayanan ANC (Antenatal Care) di Puskesmas tersebut. 


\section{Daftar Rujukan}

Depkes RI. 2010. Profil Kesehatan Indonesia

Depkes RI, 2000. Paket KIE untuk pemberdayaan Masyarakat di bidang kesehatan Ibu. Jakarta:EGC

Depkes RI, 1994. Pedoman Pelayanan Antenatal di tingkat Pelayanan Dasar Puskesmas.Jakarta. Pusdiknakes.

Dinkes Prop. Sulawesi Selatan 2011.Gambaran Antenatal Care dan Status Gizi Ibu Hamil di Pesisir Tallo Kota Makassar

Herlinti. 2011. Studi Pemanfaatan ANC Pada Ibu Hamil di Puskesmas Siderojo Pagar Alam. Medan

Ibrahim,C, 1996. Pengetahuan dan Sikap Tentang Kehamilan dengan kepatuhan Kunjungan Antenatal Care

Jumiami, 1995. Asuhan Keperawatan Perinatal . Jakarta :EGC

Manuaba IBG, (1998). Ilmu Kebidanan penyakit Kandungan dan KB Untuk pendidikan Bidan.Jakarta :EGC

Marni, 2011. Asuhan Kebidanan Pada Masa Antenatal .Yogyakarta.Pustaka Pelajar

Manuaba, 2001. Hubungan Pengetahuan lbu Hamil dengan Kepatuhan Kunjungan ANC Di Klinik Bina Bromo Ujung Lingkungan, Poltekes Medan

Mochtar, R, 1998. Sinopsis Obstetri Fisiologi Obstetri Patologi, Jakarta: EGC

Murkoff, dkk. 2006. Kehamilan :Apa Yang Anda Hadapi Bulan Perbulan -Ed, 3;Jakarta : Arcan

Notoatmodjo S, 1997. Kesehatan Masyarakat llmu dan Seni, Jakarta : Rineka Citra

Sarwono, P.2002. Buku Acuan Nasional Pelayanan Kesehatan Maternal

Safrani, 2002. Pengetahuan dan Sikap Petugas: Ilmu dan Seni :Jakarta. 